\title{
Anatomical Relationships between Eustachian Tube and Internal Carotid Artery Using Computed Tomography
}

\author{
Jae-Hoon Jung, Eui-Kyung Goh, Il-Woo Lee, Jae-Hwan Jung, Se-Joon Oh, and Soo-Keun Kong \\ Department of Otorhinolaryngology-Head and Neck Surgery, Pusan National University School of Medicine and \\ Medical Research Institute, Busan, Korea
}

\section{컴퓨터단층촬영을 이용한 이관과 내경동맥의 해부학적 위치 관계}

정재훈 · 고의경 · 이일우 · 정재환 · 오세준 · 공수근

부산대학교 의학전문대학원 이비인후과학교실

\author{
Received June 30, 2015 \\ Revised September 1,2015 \\ Accepted September 3, 2015 \\ Address for correspondence \\ Soo-Keun Kong, MD, PhD \\ Department of Otorhinolaryngology- \\ Head and Neck Surgery, \\ Pusan National University \\ School of Medicine and \\ Medical Research Institute, \\ 179 Gudeok-ro, Seo-gu, \\ Busan 49241, Korea \\ Tel $+82-51-240-7335$ \\ Fax $+82-51-246-8668$ \\ E-mail entkong@gmail.com
}

Background and Objectives It is important to figure out the location between the internal carotid artery (ICA) and the Eustachian tube (ET) for conducting safe ET surgery. Using computed tomography $(\mathrm{CT})$, this study was aimed to evaluate the anatomical relationship between ET and ICA according to age and gender.

Subjects and Method Contrast enhanced CT scans of the paranasal sinus taken between January 2005 and December 2010 were reviewed retrospectively. A total of 216 patients (432 ears) were enrolled. In each patient, we measuresed the distance from the anterior cushion of torus tubarius to ICA (AC-ICA), the distance from the posterior cushion of torus tubarius to ICA (PC-ICA), the distance from the Rosenmüller fossa to ICA, the shortest distance from ET lumen to ICA (ET-ICA), and the angle between the imaginary lines from the orifice of ET to the posterior end point of nasal septum to point ICA ( $\angle$ ET-NS-ICA). Patients were divided into 10 groups based on age difference of 15 -years.

Results For the female patients aged 65 to 80 years old, AC-ICA, PC-ICA were closest from the nasopharynx. For this group, at $p<0.05$, the distances of AC-ICA, PC-ICA and ET-ICA showed a negative correlation with increasing age, whereas $\angle$ ET-NS-ICA $(p<0.05)$ showed a positive correlation, indicating a tendency of medicalization with increased age.

Conclusion The distance between ET and ICA represents a variety of distribution according to gender and age. When performing a surgery for the nasopharyngeal portion of ET, the surgeon should be aware of the location of ICA in the preoperative CT findings.

Korean J Otorhinolaryngol-Head Neck Surg 2015;58(12):848-54

Key Words Computed tomography · Eustachian tube · Internal carotid artery.

\section{서 론}

이관(Eustachian tube, ET)은 압력 조절, 중이 보호, 정화 작용 등의 기능을 하며 중이와 인두를 연결하는 원형 공간으 로, 인두부에 가까운 연골부와 중이에 가까운 골부로 나뉜다. 이관은 성인에서 $37.5 \mathrm{~mm}$ 의 길이를 가지며, 중이의 앞벽으로 부터 비인두의 측벽까지 위치하고, 뒤쪽으로 내경동맥(internal carotid artery, ICA)의 추체부가 위치한다. 이관의 기능장애
가 있을 때, 삼출성 중이염, 유착성 중이염, 고막 천공, 진주종 성 중이염 등으로 진행될 수 있어 그 치료가 중요하며, ${ }^{1)}$ 수십 년간 이관의 기능 개선을 위해 여러 노력이 시도되어 왔다. ${ }^{2}$ 1970 년대에는 이관의 골부에 대한 이관성형술이 시행되었으 나 ${ }^{3-5)}$ 이관의 골부 협착 시에만 시행할 수 있는 제한점 이외에 술 후 스텐트의 이동, 자연방출 등의 문제점이 있었다. ${ }^{6,7)}$ 이후 비인강을 통한 이관의 연골부를 포함한 이관기능 개선에 초점 을 맞춘 치료가 시도되었는데, ${ }^{8)} 1980$ 년대 테플론, gelfoam, 지 
방 등을 이용한 이관 융기 주입술이 시행되었지만 뇌혈전증으 로 사망한 사례 등의 부작용이 보고되었다. ${ }^{9)}$ 또한 레이저와 미세흡입분쇄기를 이용한 이관 융기 부분의 절제를 통한 치료 법이 제안되었으나, 이 부위의 광범위한 절제는 내경동맥과 근 접하여 위험성이 있었다. ${ }^{10-12)} 2010$ 년 이후에도 비인강을 통한 풍선 확장 이관성형술이 고안되어 시행되고 있어 ${ }^{13)}$ 이관과 인 접한 내경동맥의 위치를 파악하는 것은 중요하다. 중이, 이관, 내 경동맥 사이의 해부학적 구조에 대해 많은 연구가 있었으나 ${ }^{14-18)}$ 이관과 내경동맥 사이의 위치관계를 성별과 연령에 따라 분석 한 연구는 극히 제한적이다.

본 연구에서는 이관과 내경동맥 사이의 위치 관계를 컴퓨터 단층촬영을 통해 계측하고, 연령 및 성별에 따라 분석하여, 비 인강을 통한 이관 수술 시 중요한 지표를 제공하고자 하였다.

\section{대상 및 방법}

2005년 1월부터 2010년 12월까지 비강 및 부비동 질환으로 부비동 컴퓨터단층촬영(contrast enhanced paranasal sinus computed tomography)을 시행한 80세 이하의 성인을 대상으 로 후향적으로 조사하였다. 216명(432귀)에 대하여 분석하였 고, 선천기형, 외상, 비인강 종양의 병력이 있는 환자는 제외하 였다. 또한 영상에서 이관의 주행경로가 명확하지 않은 경우 도 제외하였다. 남녀 각각 119 명과 97 명이었으며, 각각 15 세 간 격으로 19 세 이하 군부터 65 80세 군까지 총 5개의 군으로 나누었다.

영상 촬영은 컴퓨터단층촬영기(MDCT 16 channel; Somatom Sensation, Siemens Medical System, Berlin, German) 를 이용하여, axial $0.6 \mathrm{~mm}, \mathrm{~mA} 72$ 의 조건에서 촬영하였다.

각 환자의 이관, 내경동맥, 로젠뮬러와(Rosenmuiller fossa, $\mathrm{RF}$ )가 가장 명확한 축상면 영상을 선정하였다. 측정은 PACS system을 사용하였으며, 측정치는 $\mathrm{mm}$ 단위로 소수점 둘째 자리까지 측정하였다. 비인강에서 내경동맥까지의 거리를 측 정하기 위해, 내경동맥부터 이관의 전방 융기까지 최단 거리 (distance from anterior cushion of torus tubarius to ICA, ACICA), 후방 융기까지 최단 거리(distance from posterior cushion of torus tubarius to ICA, PC-ICA), 로젠뮬러와까지 최단 거

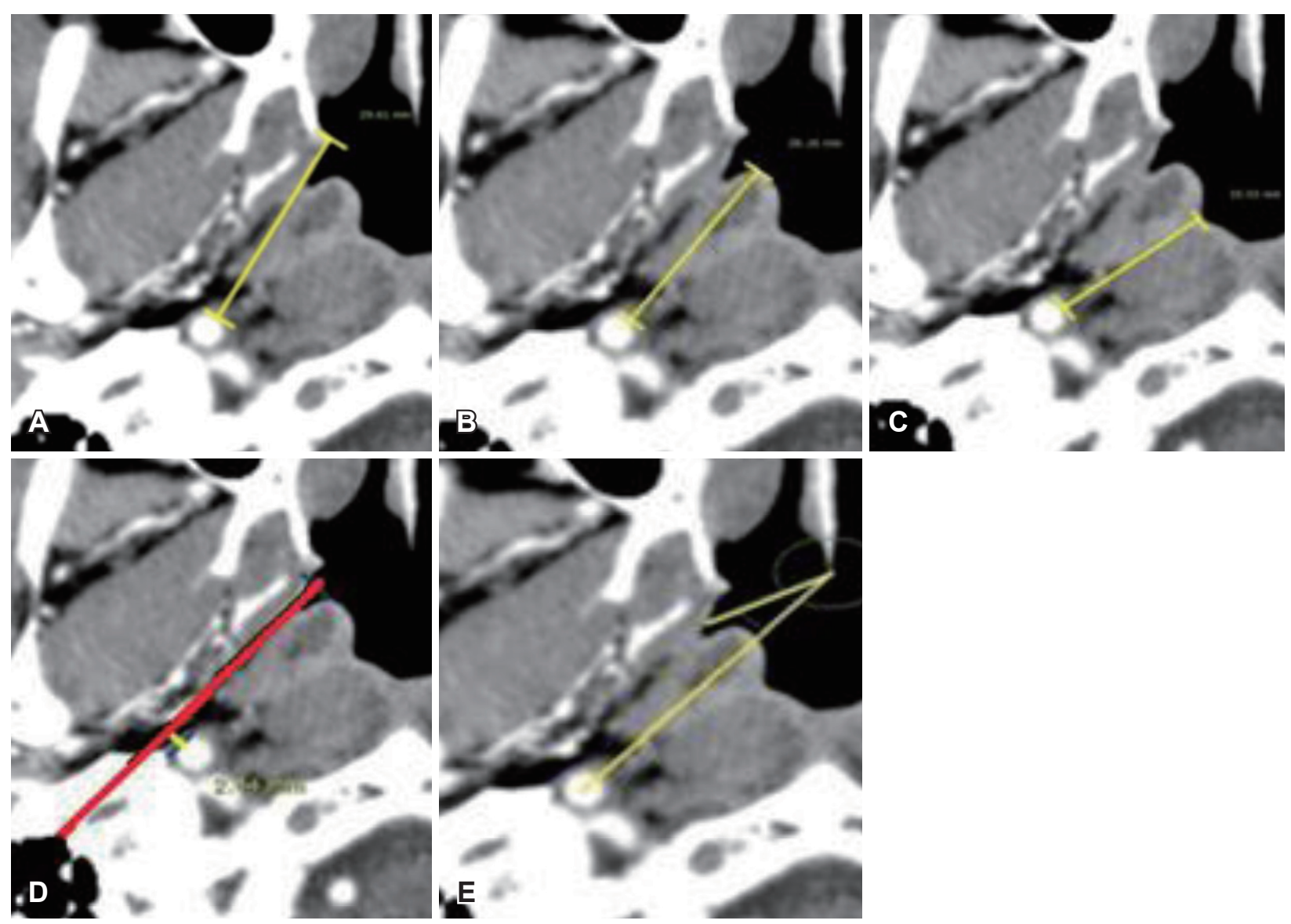

Fig. 1. Measuring parameters of right Eustachian tube (ET) (yellow line). Distance from anterior cushion of torus tubarius to internal carotid artery (ICA) (A). Distance from posterior cushion of torus tubarius to ICA (B). Distance from Rosenmüller fossa to ICA (C). Shortest distance from ET lumen (red line) to ICA (D). Angle between the imaginary line from orifice of ET to posterior end point of nasal septum and the imaginary line from posterior end point of nasal septum to ICA $(E)$. 
리(distance from RF to ICA, RF-ICA)를 각각 측정하였다 (Fig. 1A, B, and C). 또한 이관 주행부에서 내경동맥까지의 최 단 거리를 측정하기 위해, 이관 주행경로의 가상선과 내경동맥 사이의 수직 거리(shortest distance from ET lumen to ICA, ET-ICA)를 측정하였다(Fig. 1D). 이관의 주행경로가 명확하 지 않은 10 귀에서는 해당 영상의 전후 영상을 참고하여 주행 경로를 추정하여 계측하였다. 또한 이관의 전후방 융기의 중 간점, 비중격의 후방점, 내경동맥의 중앙점 사이의 각도(angle between the imaginary lines from orifice of ET to posterior end point of nasal septum to point ICA, $\angle \mathrm{ET}-\mathrm{NS}-\mathrm{ICA}$ )를 측정하였다(Fig. $1 \mathrm{E}$ ).

통계분석 프로그램(SPSS 18.0, SPSS Inc., Chicago, IL, USA)을 사용하여 통계적 검증을 하였으며, 유의수준 $p<0.05$ 인 경우 유의한 것으로 평가하였다. 나이와 측정치의 관계를 분석하기 위해 피어슨 상관관계분석(Pearson correlation analysis)을 사용하였다.

\section{결 과}

대상자의 평균 연령은 $50.45 \pm 18.71$ 세(최소 16 세, 최대 80세) 였다(Table 1).

전체 $\mathrm{AC}-\mathrm{ICA}, \mathrm{PC}-\mathrm{ICA}, \mathrm{RF}-\mathrm{ICA}$ 의 평균값은 각각 $27.77 \pm$

Table 1. Age and gender of subjects

\begin{tabular}{llrr}
\hline Characteristics & Categories & $\mathrm{n}$ & $\%$ \\
\hline Gender & Male & 119 & 55.1 \\
& Female & 97 & 44.9 \\
Age (years) & & & \\
& -19 & 13 & 6.0 \\
& $20-34$ & 45 & 20.8 \\
& $35-49$ & 34 & 15.7 \\
& $50-64$ & 64 & 29.6 \\
& $65-80$ & 60 & 27.8
\end{tabular}

$3.20 \mathrm{~mm}, 23.17 \pm 3.98 \mathrm{~mm}, 17.35 \pm 5.55 \mathrm{~mm}$ 였다. 또한 ET-ICA, $\angle \mathrm{ET}-\mathrm{NS}-\mathrm{ICA}$ 의 평균값은 각각 $5.00 \pm 1.85 \mathrm{~mm}, 15.43 \pm 6.15^{\circ}$ 였다(Table 2 and 3).

남성에서 $\mathrm{AC}-\mathrm{ICA}, \mathrm{PC}-\mathrm{ICA}, \mathrm{RF}-\mathrm{ICA}$ 의 최소값은 각각 $19.82 \mathrm{~mm}, 12.25 \mathrm{~mm}, 3.70 \mathrm{~mm}$ 였다. 이에 반해 여성에서의 $\mathrm{AC}-$ ICA, PC-ICA, RF-ICA의 최소값은 각각 $16.65 \mathrm{~mm}, 10.76 \mathrm{~mm}, 3.14$ $\mathrm{mm}$ 였다. ET-ICA의 최소값은 각각 $1.83 \mathrm{~mm}, 1.68 \mathrm{~mm}$ 였다 (Fig. 2 and Table 2). 또한 $\angle \mathrm{ET}-\mathrm{NS}-\mathrm{ICA}$ 는 최소 3.1, 최대 $43.1^{\circ}$ 로 다양하게 측정되었다(Table 3).

또한 측정치에 대한 연령과의 관계를 피어슨 상관관계분석 으로 분석한 결과, 유의수준 $p<0.05$ 에서 남성은 $\mathrm{AC}-\mathrm{ICA}$, $\mathrm{PC}-\mathrm{ICA}, \angle \mathrm{ET}-\mathrm{NS}-\mathrm{ICA}$ 에서 유의한 음의 상관관계를 나타내 어 연령이 증가할수록 내경동맥이 비인강 점막 표면에 위치함 을 알 수 있었다. 여성의 경우 AC-ICA, PC-ICA, ET-ICA에서 유의한 음의 상관관계를 나타내어 연령이 증가할수록 내경동 맥이 비인강 점막 표면에 위치함을 알 수 있었고, $\angle \mathrm{ET}-\mathrm{NS}-$ ICA에서는 유의한 양의 상관관계를 나타내어 연령이 증가할 수록 내경동맥이 내측화(medialization)됨을 알 수 있었다(Fig. 3).

\section{고 찰}

이관의 기능부전은 이과 영역에서 진단 기준이 확립되어 있 지 않으나 자주 접하게 되는 진단이다. ${ }^{19)}$ 증상은 시간에 따른 변동성이 있으며 청력저하, 이충만감, 이통, 중이압력 조절 불 가, 이명, 어지럼 등이 있다.

약물의 복용 및 중이 환기관 삽입에 반응이 없는 이관의 기 능부전의 치료에 대하여 비인강을 통한 이관 인두 개구부의 내시경 수술이 효과적일 수 있다. 레이저, 미세흡입분쇄기를 사용한 절제술, 스텐트 삽입 등의 수술이 내시경 수술 중 비교 적 안전한 수술로 사용되었다. ${ }^{20,21)}$ 그러나 이관의 침습적인 접 근이 필요한 경우, 내경동맥이 예상보다 표층에 위치한다면 내
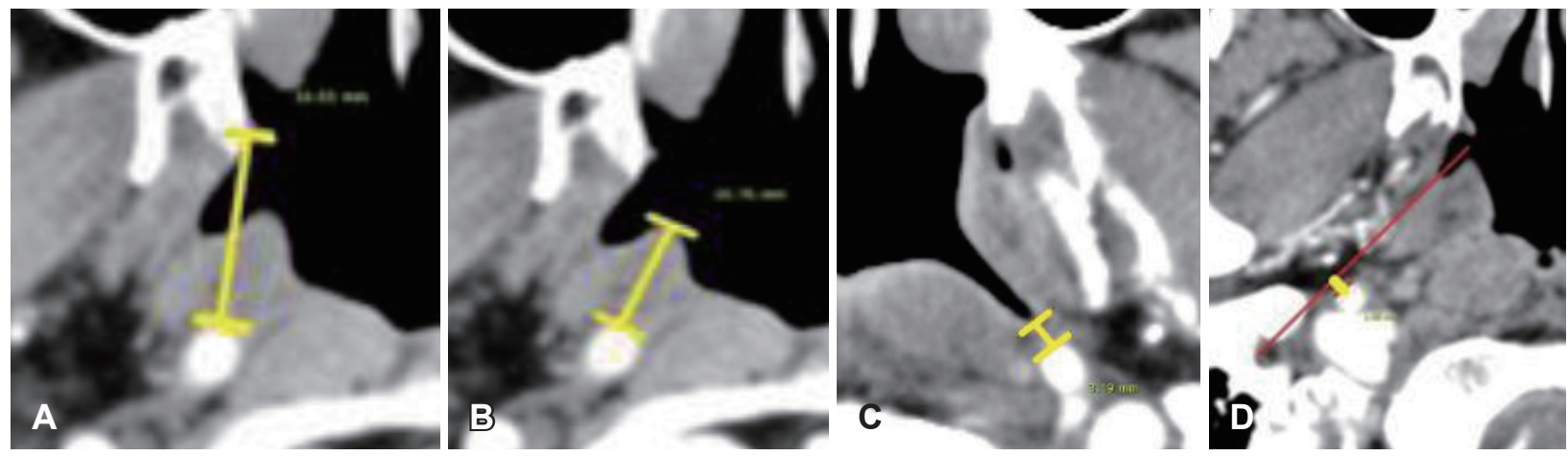

Fig. 2. Minimum value of each parameters (yellow line). Minimum value from anterior cushion of torus tubarius to internal carotid artery of female $(16.65 \mathrm{~mm})(\mathrm{A})$. Minimum value from posterior cushion of torus tubarius to internal carotid artery of female $(10.76 \mathrm{~mm})(B)$. Minimum value from Rosenmüller fossa to internal carotid artery of female $(3.14 \mathrm{~mm})(\mathrm{C})$. Minimum value from Eustachian tube lumen (red line) to internal carotid artery of female $(1.68 \mathrm{~mm})(\mathrm{D})$. 
Table 2. Result of measurements (AC-ICA, PC-ICA, RF-ICA)

\begin{tabular}{|c|c|c|c|c|c|c|c|}
\hline \multirow{2}{*}{ Gender } & \multirow{2}{*}{ Age } & \multicolumn{2}{|c|}{ AC-ICA } & \multicolumn{2}{|c|}{ PC-ICA } & \multicolumn{2}{|c|}{ RF-ICA } \\
\hline & & Mean \pm SD & Min & Mean \pm SD & Min & Mean \pm SD & Min \\
\hline \multirow[t]{5}{*}{ Male } & -19 & $29.22 \pm 1.98$ & 25.63 & $25.42 \pm 2.33$ & 21.62 & $18.78 \pm 4.73$ & 7.47 \\
\hline & $20-34$ & $29.68 \pm 2.45$ & 23.98 & $25.26 \pm 2.47$ & 19.94 & $19.31 \pm 5.26$ & 9.05 \\
\hline & $35-49$ & $28.01 \pm 3.55$ & 21.61 & $23.02 \pm 4.31$ & 14.65 & $19.35 \pm 4.63$ & 10.19 \\
\hline & $50-64$ & $28.51 \pm 3.51$ & 19.82 & $24.38 \pm 5.47$ & 12.25 & $18.94 \pm 5.18$ & 6.67 \\
\hline & $65-80$ & $28.32 \pm 2.73$ & 21.04 & $23.72 \pm 2.90$ & 16.89 & $18.31 \pm 5.82$ & 3.70 \\
\hline \multirow[t]{5}{*}{ Female } & -19 & $28.98 \pm 1.03$ & 27.99 & $22.77 \pm 0.59$ & 21.90 & $16.01 \pm 3.55$ & 11.26 \\
\hline & $20-34$ & $27.66 \pm 2.70$ & 22.62 & $21.97 \pm 4.58$ & 11.54 & $15.80 \pm 4.79$ & 7.47 \\
\hline & $35-49$ & $26.92 \pm 3.00$ & 19.50 & $22.62 \pm 3.08$ & 15.70 & $16.46 \pm 5.39$ & 4.00 \\
\hline & $50-64$ & $26.82 \pm 2.69$ & 22.37 & $21.67 \pm 3.15$ & 15.52 & $14.06 \pm 6.02$ & 3.14 \\
\hline & $65-80$ & $25.07 \pm 3.18$ & 16.65 & $20.64 \pm 3.31$ & 10.76 & $15.75 \pm 4.94$ & 5.29 \\
\hline Total & & $27.77 \pm 3.20$ & 16.65 & $23.17 \pm 3.98$ & 10.76 & $17.35 \pm 5.55$ & 3.14 \\
\hline
\end{tabular}

AC-ICA: distance from anterior cushion of torus tubarius to internal carotid artery (ICA), PC-ICA: distance from posterior cushion of torus tubarius to ICA, RF-ICA: distance from Rosenmuler fossa to ICA, Mean: mean value, Min: minimum value, SD: standard deviation

Table 3. Result of measurements (ET-ICA, $\angle E T-N S-I C A)$

\begin{tabular}{|c|c|c|c|c|c|c|}
\hline \multirow{2}{*}{ Gender } & \multirow{2}{*}{ Age } & \multicolumn{2}{|c|}{ ET-ICA } & \multicolumn{3}{|c|}{$\angle$ ET-NS-ICA } \\
\hline & & Mean \pm SD & Min & Mean \pm SD & Min & Max \\
\hline \multirow[t]{5}{*}{ Male } & -19 & $4.61 \pm 1.53$ & 2.44 & $15.61 \pm 4.43$ & 7.40 & 24.60 \\
\hline & $20-34$ & $5.38 \pm 1.52$ & 2.53 & $15.09 \pm 5.30$ & 3.10 & 25.00 \\
\hline & $35-49$ & $5.26 \pm 2.24$ & 2.37 & $15.54 \pm 8.27$ & 3.40 & 34.80 \\
\hline & $50-64$ & $4.77 \pm 1.97$ & 1.83 & $15.38 \pm 5.20$ & 4.20 & 27.60 \\
\hline & $65-80$ & $4.89 \pm 1.83$ & 1.94 & $12.94 \pm 5.11$ & 4.90 & 31.10 \\
\hline \multirow[t]{5}{*}{ Female } & -19 & $7.91 \pm 1.91$ & 5.83 & $15.41 \pm 7.23$ & 4.10 & 24.60 \\
\hline & $20-34$ & $4.97 \pm 1.77$ & 1.95 & $14.97 \pm 5.25$ & 3.10 & 24.60 \\
\hline & $35-49$ & $5.01 \pm 1.71$ & 2.17 & $15.38 \pm 6.77$ & 3.20 & 28.60 \\
\hline & $50-64$ & $4.68 \pm 1.80$ & 1.68 & $15.69 \pm 5.33$ & 4.50 & 29.80 \\
\hline & $65-80$ & $4.96 \pm 1.82$ & 2.04 & $18.86 \pm 8.04$ & 4.20 & 43.10 \\
\hline Total & & $5.00 \pm 1.85$ & 1.68 & $15.43 \pm 6.15$ & 3.10 & 43.10 \\
\hline
\end{tabular}

ET-ICA: shortest distance from Eustachian tube (ET) lumen to internal carotid artery (ICA), $\angle E T-N S-I C A$ : angle between the imaginary line from orifice of ET to posterior end point of nasal septum and the imaginary line from posterior end point of nasal septum to ICA, Mean: mean value, Min: minimum value, Max: maximum value, SD: standard deviation

경동맥 파열, 뇌혈전증, 사망과 같은 치명적인 부작용이 발생 할 수 있다. 또한 해부학적으로 약 5 40\%의 분포로 두개저에 서 내경동맥의 이상 주행이 보고되었고, ${ }^{22)}$ 내경동맥의 이상 주행을 가진 환자들의 경우에는 인두 수술 시에도 내경동맥 을 인두 종양으로 오인하는 등의 위험성이 크다.

중이, 이관, 비인두관, 내경동맥 사이의 해부학적 구조에 대 한 연구는 보고된 바 있으나 이관과 내경동맥 사이의 위치관 계를 성별과 연령에 따라 분석한 연구는 극히 제한적이다. ${ }^{23)}$

따라서 이관기능부전의 치료 중 비인강을 통한 수술을 고 려할 경우 이관과 내경동맥 사이의 나이, 성별 등의 특성에 따 른 최소 안전거리를 술전에 확인할 필요가 있고, ${ }^{24)}$ 아울러 내 경동맥의 이상 주행에 대한 고려도 필요하다. 본 연구에서 측 정한 내경동맥, 후비공의 비중격의 후방점, 이관의 전후방 융 기의 중간점 사이의 각도 $(\angle \mathrm{ET}-\mathrm{NS}-\mathrm{ICA})$ 또한 비인강을 통한 이관 수술 시 주입술이나 풍선 확장 이관성형술을 시행할 경
우 내경동맥의 위치를 파악하기 위해 고려해야 할 것이다.

본 연구에서는 비질환의 평가를 위해 행해진 조영증강 부비 동 컴퓨터단층촬영의 432 귀를 대상으로 이관 주위 구조물과 내경동맥 사이의 관계에 대하여 고찰해 보았다. AC-ICA, PC$\mathrm{ICA}$ 의 최소값은 각각 $16.65 \mathrm{~mm}, 10.76 \mathrm{~mm}$ 로 측정되었고, $\mathrm{RF}-$ $\mathrm{ICA}$ 의 최소값은 $3.14 \mathrm{~mm}, \mathrm{ET}-\mathrm{ICA}$ 의 최소값은 $1.68 \mathrm{~mm}$ 로 각 각 측정되었으며, 이는 비인강 직후방에 내경동맥이 위치할 수 있어 비인강을 통한 이관 수술 시 내경동맥으로부터 안전 영 역(safety distance)은 거의 없다는 것을 의미한다. 이는 연령 이 증가함에 따른 조직의 위축으로 체내 연부조직과 지방조직 의 양이 상대적으로 줄어듦에 기인한 것으로 추정된다. 또한 $\angle \mathrm{ET}-\mathrm{NS}-\mathrm{ICA}$ 는 여성에서 연령과 양의 상관관계를 가짐을 알 수 있었고(Fig. 3), 이를 통해 여성에서 연령이 증가할수록 내경동맥은 이관을 기준으로 내측화됨을 알 수 있었다. 여성 에서만 연령 증가에 따라 내경동맥이 내측화되는 이유는 남성 


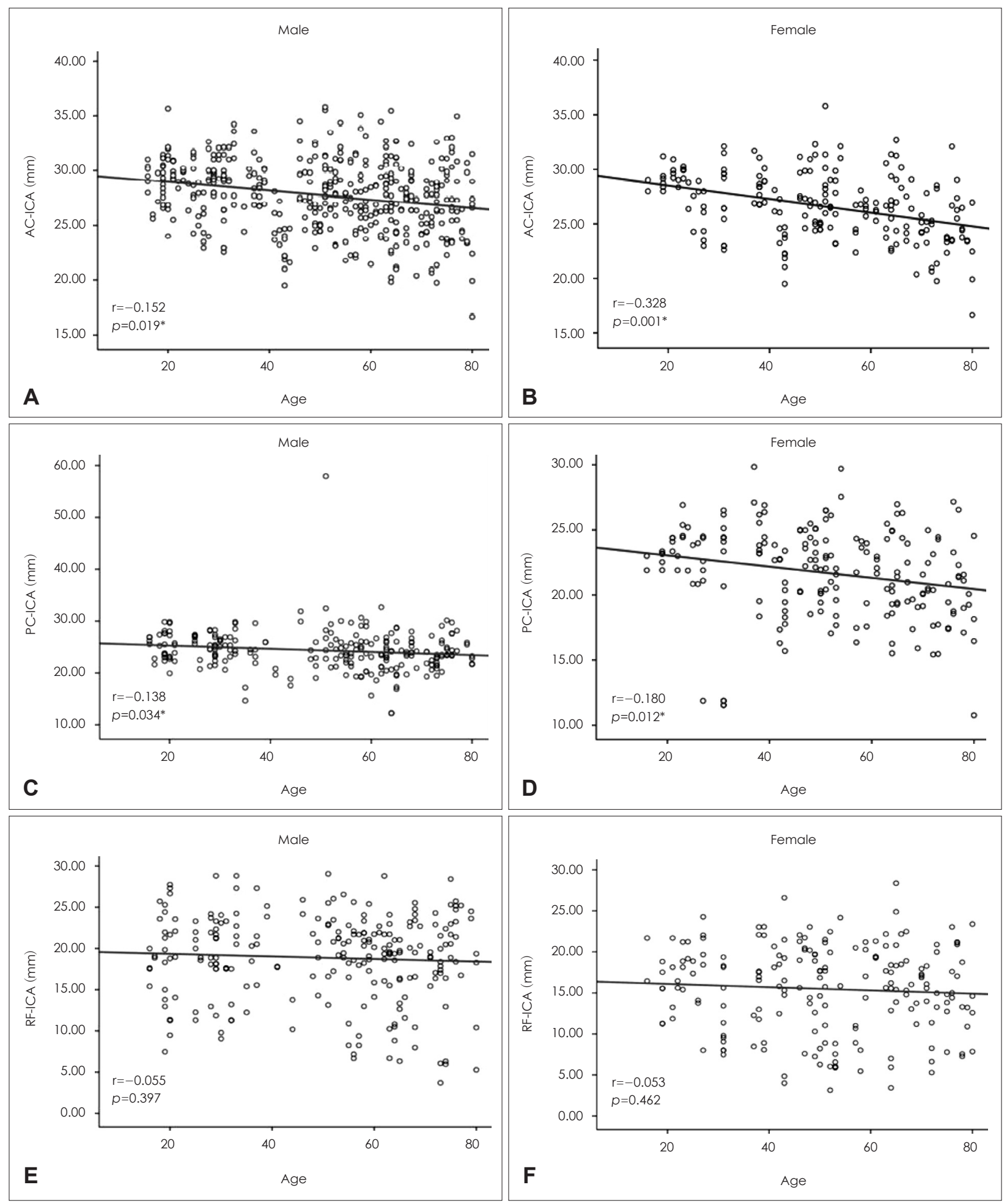

Fig. 3. Correlation analysis according to age. ${ }^{*} p<0.05$. AC-ICA, PC-ICA, ET-ICA have a negative correlation as increasing age. Especially in female, AC-ICA, PC-ICA, ET-ICA have a negative correlation and $\angle E T-N S-I C A$ has a positive correlation. On the other hand, AC-ICA, PC-ICA, LET-NS-ICA have a negative correlation in male. Correlation between age and AC-ICA in male (A). Correlation between age and AC-ICA in female (B). Correlation between age and PC-ICA in male (C). Correlation between age and PC-ICA in female (D). Correlation between age and RF-ICA in male (E). Correlation between age and RF-ICA in female (F). AC-ICA: distance from anterior cushion of torus tubarius to internal carotid artery (ICA), PC-ICA: distance from posterior cushion of torus tubarius to ICA, RF-ICA: distance from Rosenmüller fossa to ICA, ET-ICA: shortest distance from Eustachian tube (ET) lumen to ICA, $\angle E T-N S-I C A$ : angle between the imaginary line from orifice of ET to posterior end point of nasal septum and the imaginary line from posterior end point of nasal septum to ICA, PC-ICA: distance from posterior cushion of torus tubarius to ICA. (Continued to the next page) 


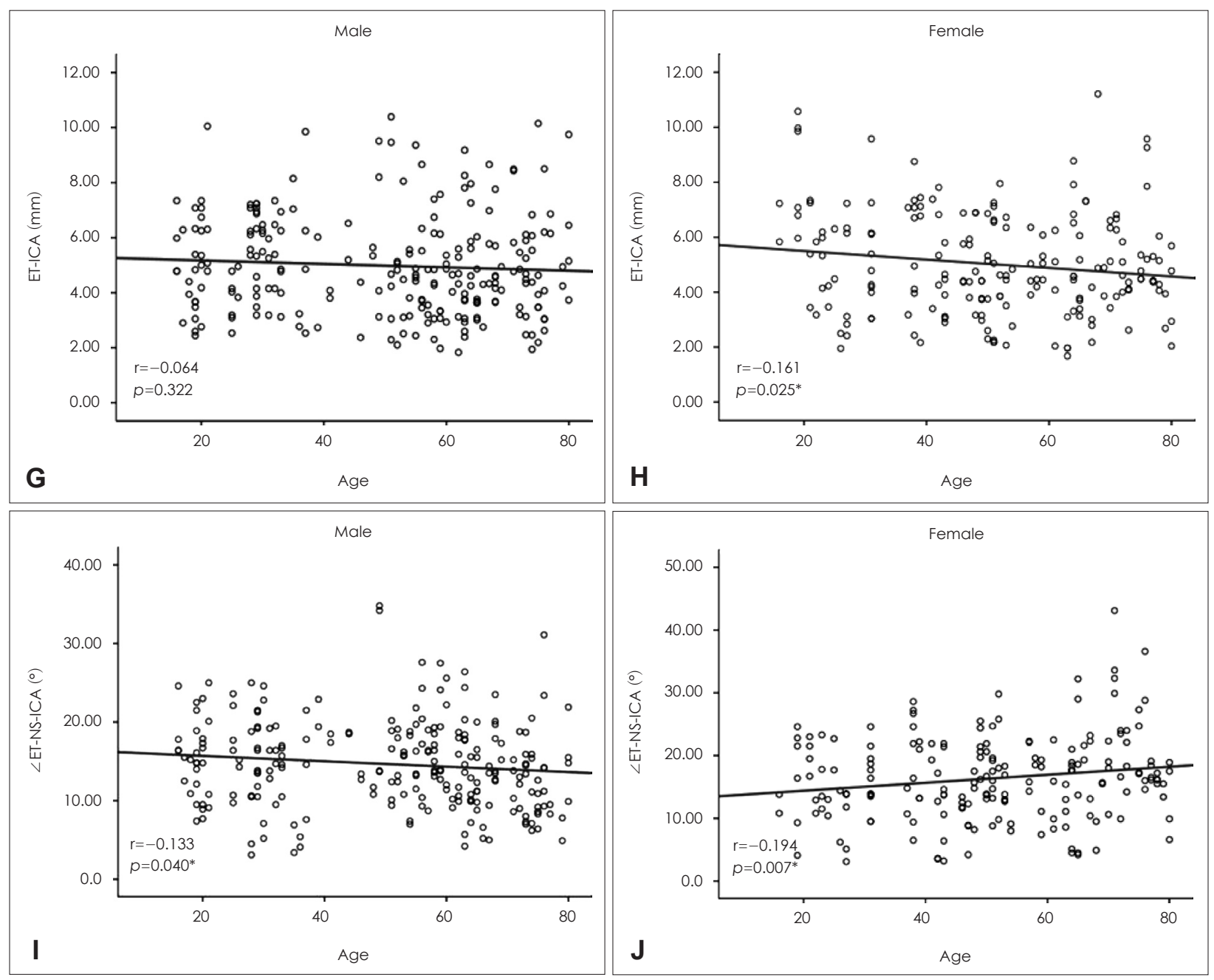

Fig. 3. (Cotinued from the previous page) Correlation between age and ET-ICA in male (G). Correlation between age and ET-ICA in female $(\mathrm{H})$. Correlation between age and $\angle E T-N S-I C A$ in male (I). Correlation between age and $\angle E T-N S-I C A$ in female (J).

에 비해 상대적으로 연부조직 및 지방조직이 많은 여성에서 노화가 진행될수록 이러한 조직의 위축이 더욱 의미 있게 진 행되어 나타난 결과로 추정된다.

이를 통해 이관 관련 수술을 시행할 경우, 고령인 환자에서 내경동맥은 통계적으로 비인강 점막에 가깝게 위치할 가능성 이 높으며, 술전에 이러한 가능성을 염두해 두고 수술에 임해 야 한다. 또한 여성의 경우, 내경동맥은 통계적으로 연령이 증 가함에 따라 보다 중앙부에 위치하게 되므로 특히 고령 여성 의 수술 시 내경동맥이 비인강 점막의 중앙부 표층에 위치할 가능성을 항상 고려해야 한다.

본 연구의 한계점은 환자가 비중격 만곡이 있는 경우 후비 공의 비중격의 후방점의 변동에 따른 좌우 수치의 가변성이 있을 수 있으며, 실제 이관은 S자 곡선 형태로 주행하지만, 본 연구에서는 직선으로 가정하여 통계를 산출하였기에 이로 인 한 오차가 있을 수 있다. 또한 부비동 컴퓨터단층촬영은 앙와 위에서 시행되나, 실제 비인강을 통한 이관 수술은 반좌위에
서 시행되기에 이로 인한 오차가 있을 수 있다.

\section{REFERENCES}

1) Seibert JW, Danner CJ. Eustachian tube function and the middle ear. Otolaryngol Clin North Am 2006;39(6):1221-35.

2) Berman S, Byrns PJ, Bondy J, Smith PJ, Lezotte D. Otitis mediarelated antibiotic prescribing patterns, outcomes, and expenditures in a pediatric medicaid population. Pediatrics 1997;100(4):585-92.

3) House WF, Glasscock ME 3rd, Miles J. Eustachian tuboplasty. Laryngoscope 1969;79(10):1765-82.

4) Misury VK. Eustachian tuboplasty. J Laryngol Otol 1975;89(8):807-13.

5) Misurya VK, Shrivastava PK. Functional eustachian tuboplasty: a new surgical technique. Arch Otolaryngol 1976;102(6):330-3.

6) Lesinski SG, Fox JM, Seid AB, Bratcher GO, Cotton R. Does the Silastic Eustachian Tube prosthesis improve eustachian tube function? Laryngoscope 1980;90(9):1413-28.

7) Parkin JL, Johnson LP, Stringham JC. Transtympanic eustachian tuboplasty and tolerance of stenting materials. Otolaryngol Head Neck Surg 1983;91(4):407-11.

8) Mathew GA, Kuruvilla G, Job A. Dynamic slow motion video endoscopy in eustachian tube assessment. Am J Otolaryngol 2007;28 (2):91-7.

9) O'Connor AF, Shea JJ. Autophony and the patulous eustachian 
tube. Laryngoscope 1981;91(9 Pt 1):1427-35.

10) Kujawski OB, Poe DS. Laser eustachian tuboplasty. Otol Neurotol 2004;25(1):1-8

11) Poe DS, Grimmer JF, Metson R. Laser eustachian tuboplasty: twoyear results. Laryngoscope 2007;117(2):231-7.

12) Metson R, Pletcher SD, Poe DS. Microdebrider eustachian tuboplasty: a preliminary report. Otolaryngol Head Neck Surg 2007;136(3):422-7.

13) Ockermann T, Reineke U, Upile T, Ebmeyer J, Sudhoff HH. Balloon dilatation eustachian tuboplasty: a clinical study. Laryngoscope 2010; 120(7):1411-6.

14) Anson BJ. Critical distances in the middle and inner ear and in the posterior cranial fossa. Trans Am Acad Ophthalmol Otolaryngol 1972;76(1):108-29.

15) Sudo M, Sando I, Suzuki C. Three-dimensional reconstruction and measurement study of human eustachian tube structures: a hypothesis of eustachian tube function. Ann Otol Rhinol Laryngol 1998;107 (7):547-54.

16) Aslan A, Balyan FR, Taibah A, Sanna M. Anatomic relationships between surgical landmarks in type $\mathrm{b}$ and type $\mathrm{c}$ infratemporal fossa approaches. Eur Arch Otorhinolaryngol 1998;255(5):259-64.

17) Hasebe S, Sando I, Orita Y. Proximity of carotid canal wall to tympanic membrane: a human temporal bone study. Laryngoscope 2003;113 (5):802-7.

18) Maheshwar AA, Kim EY, Pensak ML, Keller JT. Roof of the parapharyngeal space: defining its boundaries and clinical implications. Ann Otol Rhinol Laryngol 2004;113(4):283-8.

19) Randrup TS, Ovesen T. Balloon eustachian tuboplasty: a systematic review. Otolaryngol Head Neck Surg 2015;152(3):383-92.

20) Poe DS. Laser-assisted endoscopic stapedectomy: a prospective study. Laryngoscope 2000;110(5 Pt 2 Suppl 95):1-37.

21) Shapshay SM. Laser applications in the trachea and bronchi: a comparative study of the soft tissue effects using contact and noncontact delivery systems. Laryngoscope 1987;97(7 Pt 2 Suppl 41):1-26.

22) Weibel J, Fields WS. Tortuosity, coiling, and kinking of the internal carotid artery. I. Etiology and radiographic anatomy. Neurology 1965; 15:7-18.

23) Bergin M, Bird P, Cowan I, Pearson JF. Exploring the critical distance and position relationships between the Eustachian tube and the internal carotid artery. Otol Neurotol 2010;31(9):1511-5.

24) Tsunoda K, Takanosawa M, Matsuda K. Aberrant internal carotid artery in the mouth. Lancet 1997;350(9074):340. 